\section{CME: A variety of conditions}

This month's CME is once again made up of a series of case reports covering a variety of conditions, including entities such as the littleknown Kounis syndrome.

The wonderful thing about case reports is that they can be about just about anything. While they are seldom peer reviewed and are certainly not regarded as research, they are very useful entities. Simple reporting is one of their functions - alerting clinicians to potential problems of well-known diseases that may not have surfaced in someone else's experience. They can also be used to alert people to unexpected drug side-effects - ataxia in children taking efavirenz, for example. There is even a Journal of Medical Case Reports, which I find fascinating reading. If you have a broad interest in all things medical, this is for you.

Case reports should highlight clinical concerns - such as the importance of taking a good history, the pitfalls of assumptions, and descriptions of rare or even novel clinical entities.

\section{Bronchial thermoplasty and endoscopic lung volume reduction}

A 'Forum' article by Dheda et al. ${ }^{[1]}$ introduces practitioners to indications for the use of bronchial thermoplasty in severe asthma, while Koegelenberg et al. ${ }^{[2]}$ provide recommendations for endoscopic lung volume reduction (ELVR) in emphysema. ${ }^{[2]}$ It is recommended that all ELVR procedures should be performed in the context of a local and/or international registry.

The Assembly on Interventional Pulmonology of the South African Thoracic Society is willing to assist potential centres wishing to establish an ELVR service in terms of training and accreditation.

\section{South Africa (SA)'s burden of trauma and violence}

This month's SAMJ highlights SA's frightful record of trauma (interpersonal violence, burns, motor vehicle crashes and pedestrian injury - particularly in children ${ }^{[3]}$ ). The evidence resides in several articles from those working in emergency centres and trauma/ surgical units ${ }^{[4,5]}$ and in forensic pathology. ${ }^{[6]}$

Naidoo and Muckart ${ }^{[3]}$ show in 'The wrong and wounding road: Paediatric polytrauma admitted to a level 1 trauma intensive care unit over a 5-year period' that motor vehicle-related injuries, especially those involving pedestrians, dominate severe paediatric trauma (see Table 1 in the article), and stress that there is an urgent need for more road traffic education and stringent measures to decrease the incidence and associated morbidity and mortality. Our little ones (aged up to 10 years) simply have no experience of road traffic, and SA drivers have no culture of caring for or slowing down for pedestrians. Motor vehicle collisions accounted for $88.4 \%$ of deaths. Of the 181 injured children, 112 (61.9\%) had traumatic brain injury, of the 26 children who died, 23 (88.4\%) had associated head trauma, and in 18 deaths (69.2\%) severe traumatic brain injury was the primary cause. There is an urgent need for more road traffic education and stringent measures to decrease the incidence and associated morbidity and mortality.

Importantly, as the authors point out, their mortality statistics do not reflect the extent of the trauma problem, as their results exclude deaths at the scene and address only critically injured children admitted to a level 1 trauma intensive care unit. Of children with severe traumatic brain injury who survive, many are permanently disabled for life, and in the public sector have little access to adequate rehabilitation facilities. And for every severely injured child there are many more who have suffered less devastating injuries and are admitted to regional or district hospitals. The psychological, physical and economic burdens that are imposed on the individual, family and society are incalculable.

For young passengers, the SA Law on Seatbelts in Regulation 213 of the National Road Traffic Act in force since 30 April 2015 stipulates that the driver of a motor vehicle operating on a public road shall ensure that a child seated on a seat of the motor vehicle uses an appropriate child restraint if it is available in the motor vehicle, or if no child restraint is available, wears a seatbelt if an unoccupied seat is fitted with one. Similarly, the driver of such a motor vehicle shall ensure that an infant travelling in the vehicle is seated on an appropriate child restraint. However, there is a big 'but': these provisions do not apply in the case of 'a minibus or bus operating for reward'.

A retrospective analysis of 777 major incidents registered in the Western Cape Major Incident database for the period 2008 - 2014 (Van Hoving et al., ${ }^{[4]}$ 'The epidemiology of major incidents in the Western Cape Province, South Africa') showed that road traffic crashes were the biggest contributor (in 94\%). ${ }^{[4]}$ Most major incidents occurred in the City of Cape Town $(57.8 \%, n=449)$, but the Central Karoo district (long, boring road) had the highest incidence (11.97/10 000 population). Surely to no one's surprise, minibus taxis were involved in $40 \%$ of crashes. A total of 8732 patients were injured (median per incident 8.0), and ten incidents involved 50 or more victims! Most patients were adults $(80 \%, n=6986)$ and male $(51 \%$, $n=4455$ ), and more than half of the patients sustained minor injuries $(54.6 \%, n=4605)$. The authors call for a national database that will provide a full perspective of the burden of major incidents.

In 'Meeting national response time targets for priority 1 incidents in an urban emergency medical services system in South Africa', Stein et al. ${ }^{[7]}$ elegantly show that more ambulances won't help. Modelling a number of scenarios showed that the target of $90 \%$ of responses within 15 minutes was not achieved despite a $150 \%$ increase in vehicles (see Fig. 1 in the article, reproduced below).

Moreover, since each equipped and staffed ambulance costs some ZAR3.5 million, the total cost of a modest (14\%) improvement in response time would be in the range of ZAR195 million. For decision-makers in SA emergency medical services systems, the key to improving response time performance in high-acuity cases is optimal vehicle utilisation and efficiency, rather than increasing numbers. A rethink of outdated decades-old models of response system design is required.

Violence remains the leading cause of death in SA, accounting for more than one-third of all unnatural deaths, as a 10-year review of fatal community assault cases at a regional forensic pathology facility in Cape Town ${ }^{[6]}$ confirms. Community assaults, also known

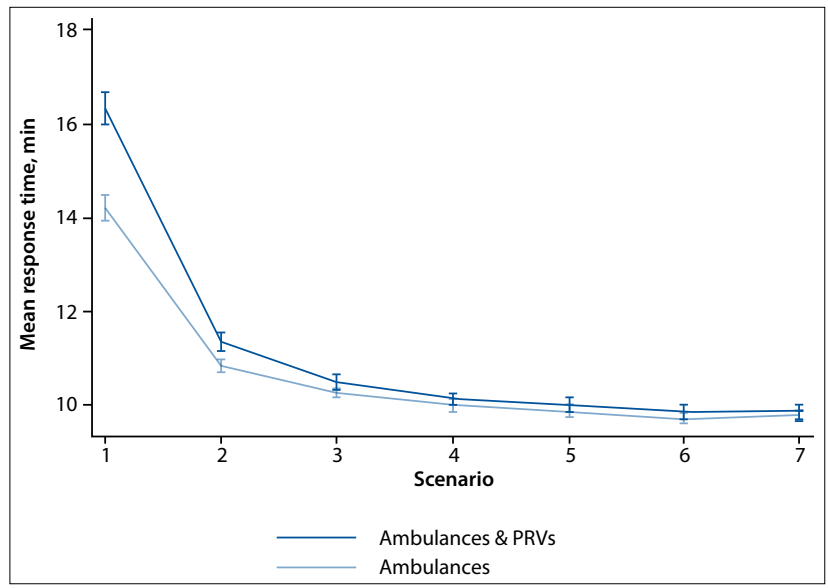

Fig. 1. Mean response times for both models. (Error bars indicate 95\% CIs.) 
as bundu or kangaroo courts and sometimes mob killings or vigilante justice, are attributed to community members who, dissatisfied with the lack of adequate law enforcement, take the law into their own hands. These so-called acts of vigilantism were a significant topic during the Khayelitsha Commission of Inquiry held in 2014.

Highlighted by Newton et al ${ }^{[8]}$ in a study of the appropriateness of emergency medical service responses in the eThekwini district of KwaZulu-Natal is the tendency on the part of the citizenry to pervert the emergency (ambulance) responses, sometimes for no other reason than to obtain transport to a local clinic, costing the country a fortune and prejudicing responses to those in real need of emergency care.

All the above research papers offer important data for the health and transport (and justice) ministries, at national and provincial levels. The cost to the fiscus in terms of hospitalisation, rehabilitation, funeral services and loss of the family breadwinner can only be imagined!

\section{Burn services in the Western Cape}

A further major source of trauma continues to be burns, as Rode et al ${ }^{[9]}$ reveal in their review of primary and secondary burn services in the Western Cape. More than half of those affected are children, the incidence is highest in the winter months, and hot liquid scalds remain the most frequent cause. The majority of burn injuries are minor and are satisfactorily managed at primary level, patients being treated by nurse practitioners and discharged. However, there are considerable delays in the transfer of more severe cases, and pain control is insufficient. The four regional secondary hospitals in the province manage the majority of moderate to severe burns. Rode et al. point out that there is room for improvement in terms of treatment facilities and consumables at all levels. Ten strategies are offered that could, if implemented, lead to tangible improvements in management of burn patients at primary and secondary levels in the Western Cape and around the country. Regional hospitals are particularly restricted by outdated equipment, a shortage of intensive care unit beds, and difficulties in transferring patients with major burns to a specialised burns unit when indicated.

\section{Reducing the risk of nosocomial transmission of pulmonary tuberculosis (TB)}

Given the high burden of TB in SA and absent or rudimentary infection control procedures in the humming emergency centre (EC) units in which patients with TB are often first seen, EC staff and patients are at high risk of nosocomial infection. Asking whether infection control can be improved to lower the risk of nosocomial transmission, Casey et al.$^{[10]}$ surveyed the situation at George Regional Hospital, a 272-bed referral hospital that serves the Eden and Central Karoo districts of the Western Cape. They sought to establish the burden of pulmonary TB presenting to George Hospital via the $\mathrm{EC}$ and to audit current infection prevention and control practices regarding patients with pulmonary $\mathrm{TB}$ to determine whether these measures were inadequate and required design of new practices.

They concluded that implementation of simple adjustments to assessment and management of patients with suspected TB in the EC significantly reduced the length of patient stay, with a consequent reduction in the risk to both staff and waiting patients. Further improvements are envisaged, e.g. creation of a sputum collection room and regular assessment of the ventilation system in the EC that would further decrease the risk of infection. The impact of these measures will be studied in the near future.

JS

1. Dheda K, Koegelenberg CFN, Esmail A, et al. Indications for the use of bronchial thermoplasty in severe asthma. S Afr Med J 2015;105(10):808-809. [http://dx.doi.org/10.7196/SAMJnew.8208]

2. Koegelenberg CFN, Theron J, Dheda $K$ et al. Recommendations for the use of endoscopic lung volume reduction in South Africa: Role in the treatment of emphysema. S Afr Med J 2015;105(10):810-815, [http://dx.doi.org/10.7196/SAMJnew.8147]

3. Naidoo R, Muckart D. The wrong and wounding road: Paediatric polytrauma admitted to a level I trauma intensive care unit over a 5-year period. S Afr Med J 2015;105(10):823-826. [http://dx.doi. org/10.7196/SAMJnew.8090]

4. Van Hoving DJ, Lategan HJ, Wallis LA, Smith WP. The epidemiology of major incidents in the Western Cape Province, South Africa. S Afr Med J 2015;105(10):831-834. [http://dx.doi.org/10.7196/ SAMInew.7766]

5. Sothmann J, Stander J, Kruger N, Dunn R. Epidemiology of acute spinal cord injuries in the Groote Schuur Hospital Acute Spinal Cord Injury (GSH ASCI) Unit, Cape Town, South Africa, over the past 11 years. S Afr Med J 2015;105(10):835-839. [http://dx.doi.org/10.7196/SAMJnew.8072]

6. Herbst CI, Tiemensma M, Wadee SA. A 10-year review of fatal community assault cases at a regional forensic pathology facility in Cape Town, South Africa. S Afr Med J 2015;105(10):848-852. [http:// dx.doi.org/10.7196/SAMJnew.8274]

7. Stein C, Wallis L, Adetunji O. Meeting national response time targets for priority 1 incidents in an urban emergency medical services system in South Africa: More ambulances won't help. S Afr Med J 2015;105(10):840-844. [http://dx.doi.org/10.7196/SAM]new.8087]

8. Newton PR, Naidoo R, Brysiewicz P. The appropriateness of emergency medical service responses in the eThekwini district of KwaZulu-Natal, South Africa. S Afr Med J 2015;105(10):844-847. [http://dx.doi.org/10.7196/SAMJnew.8273]

9. Rode $\mathrm{H}$, Rogers $\mathrm{AD}$, Numanoglu A, et al. A review of primary and secondary burn services in the Western Cape, South Africa. S Afr Med J 2015;105(10):853-857. [http://dx.doi.org/10.7196/ SAMJnew.8187]

10. Casey H, Smith A, Parker L, et al. Pulmonary tuberculosis in a South African regional emergency centre: Can infection control be improved to lower the risk of nosocomial transmission? S Afr Med J 2015;105(10):862-865. [http://dx.doi.org/10.7196/SAMJnew.7813]

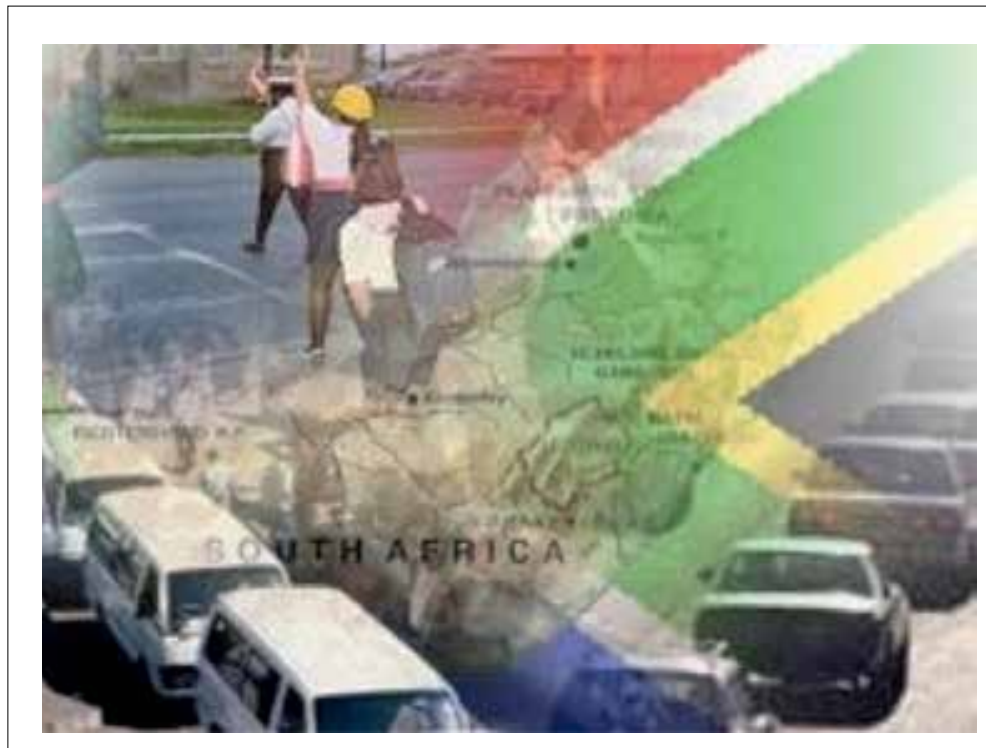

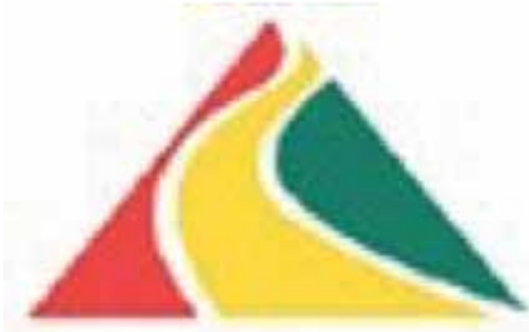

ARRIVE ALIVE

www.arrivealive.co.za

17 Years of online mosarth

Keeping South Africa's drivers on the straight and narrow. (Images: ArriveAlive.co.za) 